\title{
Applications and Implications of Heparin and Protamine in Tissue Engineering and Regenerative Medicine
}

\author{
Judee Grace E. Nemeno, Soojung Lee, Wojong Yang, Kyung Mi Lee, and Jeong Ik Lee
}

Regenerative Medicine Laboratory, Center for Stem Cell Research, Department of Biomedical Science and Technology, Institute of Biomedical Science \& Technology (IBST), Konkuk University, Seoul 143-701, Republic of Korea

Correspondence should be addressed to Jeong Ik Lee; jeongik@konkuk.ac.kr

Received 28 February 2014; Accepted 14 May 2014; Published 3 June 2014

Academic Editor: Jun Liao

Copyright ( 2014 Judee Grace E. Nemeno et al. This is an open access article distributed under the Creative Commons Attribution License, which permits unrestricted use, distribution, and reproduction in any medium, provided the original work is properly cited.

\begin{abstract}
Drug repositioning is one of the most rapidly emerging fields of study. This concept is anchored on the principle that diseases have similar damaged or affected signaling pathways. Recently, drugs have been repositioned not only for their alternative therapeutic uses but also for their applications as biomaterials in various fields. However, medical drugs as biomaterials are rarely focused on in reviews. Fragmin and protamine have been recently the sources of increasing attention in the field of tissue engineering and regenerative medicine. Fragmin and protamine have been manufactured primarily as a safe antidote for the circulating heparin. Lately, these drugs have been utilized as either micro- or nanoparticle biomaterials. In this paper, we will briefly describe the concept of drug repositioning and some of the medical drugs that have been repurposed for their alternative therapeutic uses. Also, this will feature the historical background of the studies focused on fragmin/protamine micro/nanoparticles (F/P M/NPs) and their applications as biomaterials in tissue engineering, stem cell therapy, and regenerative medicine.
\end{abstract}

\section{Introduction}

Since the birth of tissue engineering, various diseases have been addressed through the biofabrication of engineered cells or tissues, either made up of scaffolds or scaffold-free. In congruence to this, drug repositioning strategy has also progressed and has been significantly applied in various therapeutic strategies including drug-based and stem cellbased therapies through their applications in generating biomimetic constructs. Hence, advancement in tissue engineering as well as regenerative medicine has been enhanced due to some repositioned drugs.

Originally, drug rescue or repositioning is deemed as an effective strategy against the laborious and highly expensive de novo drug discovery as well as stagnant approval system of new drugs [1]. The first repositioned drug was actually an abandoned medicine, zidovudine (azidothymidine), for cancer due to lack of evidence for its effectiveness. However, it was later discovered to be effective in treating patients who are suffering from human immune deficiency virus
(HIV) or acquired immunodeficiency syndrome (AIDS) [2, 3]. From then on, many groups have been motivated to explore other approved drugs for their alternative therapeutic uses.

Lately, fragmin and protamine have been few of the leading drugs repurposed as biomaterials in tissue engineering, stem cell therapy, and regenerative medicine. Fragmin and protamine have been utilized as biomaterials, either as microparticles (MPs) or as nanoparticles (NPs), in designing tissue constructs. Recent studies show that they are useful in cell-based therapy in various fields including cardiovascular [4,5], dental [6], and dermatological medicine $[7,8]$.

In this review, we will briefly describe the concept of drug repositioning and some of the drugs that have been repurposed for other indications. Also, this will feature the historical background of the studies focused on frag$\mathrm{min} /$ protamine micro/nanoparticles (F/P M/NPs) and their applications as biomaterials in tissue engineering, stem cell therapy, and regenerative medicine. 


\section{Review}

2.1. Drug Repositioning Strategy and Its Implications in Tissue Engineering and Regenerative Medicine. Drug repurposing or repositioning strategy has been rapidly emerging in the recent years [2,9]. The trend shows that there is an increasing pattern of drug repositioning research in the academic field rather than the industrial area parallel to the shift of the greater number of scientists in the academe from the pharmaceutical industries [10]. Thus, it is expected that a number of drug discoveries and drug repositioning effort will continue to accumulate from these academic institutions compared to those that can be generated from the pharmaceutical companies.

Initially, this strategy was adapted to address the pitfalls of the previous research and development related to the interactions, safety, and efficacy of drugs. Repurposing drugs involves the reevaluation of the currently approved or even the abandoned drugs for their alternative therapeutic potentials [2]. This strategy has efficiently reduced the high cost of traditional and time-consuming drug testing and screening, lessened the clinical risks, and accelerated the progress of academic research focused not only on approved drugs but also on safety-tested but unapproved drugs $[10,11]$.

Since the repositioning of AZT [3] in 1987, a number of drugs have been repurposed for their alternative indications. To name a few, Viagra (Sildenafil) [12], a drug for angina pectoris and hypertension, has been used to treat erectile dysfunction; aspirin which was originally manufactured as an antipyretic and an anti-inflammatory drug has been indicated for hypertension and antiplatelet aggregation and has been established to exhibit cardiac protective function [13]; Rogaine (Minoxidil), an antihypertensive drug, has been used to treat baldness [14]; and tocilizumab, an antirheumatism drug, has been lately demonstrated to have therapeutic effects on amyotrophic lateral sclerosis (ALS) [15] and cancer [16]. The rest of the repositioned drugs during the 20th century include Amphocin (Amphotericin B), Rogaine (Minoxidil), Thalidomide (Thalidomide), Avodart (Dutasteride), Neurontin (Gabapentin), Symmetrel (Amantadine), Zyban (Bupropion), ReQUIP (Ropinirole), Aspirin (acetylsalicylic acid), Gemzar (Gemcitabine), Evista (Raloxifene), Viagra (Sildenafil), Yentreve (Duloxetine), Trexall (Methotrexate), and Parlodel (Bromocriptine) [17-28]. A summary of these drugs, along with their alternative therapeutic uses and their respective year of repurposing, is presented in Table 1.

Lately, a number of drugs have been applied in tissue engineering and regenerative medicine including warfarin [29], avastin [30-32], and a number of parenteral drugs [33]. Moreover, fragmin and protamine, either as MPs or as NPs, have been the leading drugs repurposed as biomaterials in tissue engineering and regenerative medicine.

\subsection{Historical Background of Fragmin/Protamine} Micro/Nanoparticles as a Drug Repositioning Strategy. Fragmin and protamine have been progressively used not only in the field of tissue engineering but also in regenerative medicine. The use of protamine under the concept of drug repositioning dates back to the 1930s when this positively charged polypeptide, obtained from the sperm of California rainbow trout, was added to the neutral protamine hagedorn insulin to prolong its effect in maintaining hypoglycemia up to 24 hours in patients who have severe diabetes mellitus $[34,35]$. The long-lasting effect of insulinprotamine combination was further enhanced when a certain amount of zinc was used to stabilize the complex and it was proven to sustain low blood glucose level up to three days after injection in diabetic patients [36]. In the later decades, protamine has been utilized primarily as a safe antidote for the circulating heparin after stent implantation. Administration of protamine demonstrated beneficial effects since it reduced the hospital stay of the patients free of medical complication after stent implantation [37]. The succeeding report showed that heparin has been clinically utilized as the prophylaxis and treatment of deep venous thrombosis (DVT) and that their molecular weight distributions significantly influence their binding properties with protamine [38].

Later on, these F/P MPs have been utilized as carriers of various stem cells, namely, adipose tissue-derived stromal cells (ASCs) and inbred rat adipose tissue-derived stromal cells (IR-ASCs) in an ordinary monolayer and a 3D culture system, respectively. The data revealed that F/P MPs improved the viabilities of the cells, induced their eventual aggregation, increased the proliferation rate, and promoted speedy neovascularization and tissue granulation after transplantation [39-41]. Moreover, F/P MPs have been found to be efficient cell carriers not only for single cell types but also for cocultured cells such as that in the 3D expansion of ASCs and bone marrow-derived mesenchymal stem cells (BMSCs). The cocultured cells also exhibited rapid proliferation rate and multilineage differentiation while maintaining their markers in spite of low serum content during the culture period [42]. Recently, F/P MPs coating method is useful for maintaining the quiescent state of rat hepatic stellate RI-T cells (HSCs) with low expressions of collagen I $\alpha \mathrm{I}$ and TGF- $\beta 1 \mathrm{mRNA}$ levels [43].

Furthermore, another report demonstrated that F/P MPs can function as immobilizers or attractants of various cytokines as well as deliberate controllers for drug release. $\mathrm{F} / \mathrm{P}$ controlled the gradual release of heparin-binding growth factors like fibroblast growth factor-2 (FGF-2) and cytokines such as interleukin- (IL-) 3, granulocyte-macrophage colonystimulating factor (GM-CSF), stem cell factor (SCF), thrombopoietin (Tpo), and Flt-3 ligand into the culture media. Consequently, F/P promoted the superior cell growth of human microvascular endothelial cells (hMVECs), human dermal fibroblast cells (hDFCs), hematopoietic cell line (TF1), hematopoietic progenitor cells (HCs), human ASCs, and BMSCs. Therefore, it is notable that $\mathrm{F} / \mathrm{P} \mathrm{M} / \mathrm{NPs}$ serve as coating biomaterials that adequately regulate the heparinbinding cytokines responsible for controlling cellular growth and differentiation $[41,42,44]$.

It has also been found that $\mathrm{F} / \mathrm{P} \mathrm{M} / \mathrm{NPs}$ can control the release of FGF-2 and significantly promote neovascularization and tissue formation one week after they were coinjected at the injured site. A recent study was conducted using mice models where the mitogenic effects of hepatocyte growth 
TABLE 1: List of repositioned drugs with their corresponding year of approval, alternative therapeutic uses, and year of repurposing.

\begin{tabular}{|c|c|c|c|c|c|}
\hline Drug name & $\begin{array}{c}\text { Year of } \\
\text { approval }\end{array}$ & $\begin{array}{c}\text { Original } \\
\text { target disease }\end{array}$ & $\begin{array}{c}\text { Year of } \\
\text { repositioning }\end{array}$ & Alternative indication & References \\
\hline $\begin{array}{l}\text { Zidovudine } \\
\text { (azidothymidine, AZT) }\end{array}$ & 1964 & Cancer & 1987 & HIV/AIDS & {$[3]$} \\
\hline $\begin{array}{l}\text { Amphocin } \\
\text { (Amphotericin B) }\end{array}$ & 1955 & Fungal infections & 1997 & Leishmaniasis & {$[17]$} \\
\hline $\begin{array}{l}\text { Rogaine } \\
\text { (Minoxidil) }\end{array}$ & 1988 & Hypertension & 1998 & Baldness, loss of hair & {$[14]$} \\
\hline $\begin{array}{l}\text { Thalidomide } \\
\text { (Thalidomide) }\end{array}$ & 1957 & Morning sickness & $\begin{array}{l}1998 \\
2006\end{array}$ & Hansen's disease/multiple myeloma & {$[18]$} \\
\hline $\begin{array}{l}\text { Avodart } \\
\text { (Dutasteride) }\end{array}$ & 1996 & Prostatic hyperplasia & 2002 & Baldness, loss of hair & {$[19]$} \\
\hline $\begin{array}{l}\text { Neurontin } \\
\text { (Gabapentin) }\end{array}$ & 2000 & Epilepsy & 2002 & Neuropathic pain & {$[20]$} \\
\hline $\begin{array}{l}\text { Symmetrel } \\
\text { (Amantadine) }\end{array}$ & 1966 & Influenza & 2003 & Parkinson's disease & {$[21]$} \\
\hline $\begin{array}{l}\text { Zyban } \\
\text { (Bupropion) }\end{array}$ & 1997 & Depression & 2005 & Smoking cessation & {$[22]$} \\
\hline $\begin{array}{l}\text { ReQUIP } \\
\text { (Ropinirole) }\end{array}$ & 1998 & Parkinson's disease & 2005 & Restless leg syndrome & {$[23]$} \\
\hline $\begin{array}{l}\text { Aspirin } \\
\text { (Acetylsalicylic acid) }\end{array}$ & 1899 & Inflammation, pain & 2006 & Antiplatelet aggregation & {$[13]$} \\
\hline $\begin{array}{l}\text { Gemzar } \\
\text { (Gemcitabine) }\end{array}$ & 1996 & Viral disease & 2007 & Cancer & {$[24]$} \\
\hline $\begin{array}{l}\text { Evista } \\
\text { (Raloxifene) }\end{array}$ & 1997 & Breast cancer & 2007 & Osteoporosis & {$[25]$} \\
\hline $\begin{array}{l}\text { Viagra } \\
\text { (Sildenafil) }\end{array}$ & 1998 & Angina, hypertension & 2007 & Erectile dysfunction & {$[12]$} \\
\hline $\begin{array}{l}\text { Yentreve } \\
\text { (Duloxetine) }\end{array}$ & 2004 & Depression & 2007 & Stress urinary incontinence & {$[26]$} \\
\hline $\begin{array}{l}\text { Trexall } \\
\text { (Methotrexate) }\end{array}$ & 1946 & Cancer & 2009 & Psoriasis, rheumatoid arthritis & {$[27]$} \\
\hline $\begin{array}{l}\text { Parlodel } \\
\text { (Bromocriptine) }\end{array}$ & 1988 & Parkinson's disease & 2009 & Diabetes mellitus & {$[28]$} \\
\hline
\end{tabular}

factor- (HGF-) containing F/P MPs on cultured MVECs and their angiogenic potentials were evaluated. The results of the study suggest that HGF is highly activated, parallel to the adsorption of F/P MPs, and that $\mathrm{HGF}$ release is correlated to the diffusion and/or biodegradation of the $\mathrm{F} / \mathrm{P}$ MPs. Finally, HGF-containing F/P MPs induce substantial cell proliferation and vascularization in vivo. This increased angiogenic activity of HGF in vivo was probably due to both sustained local release and protection against biodegradation by the F/P MPs [5]. Also, F/P MPs promoted collateral vessel formation in peripheral artery disease (PAD) models when applied with FGF-2 [4, 45].

Another important use of F/P MPs is that they serve as competent carriers of the proteins present in human platelet-rich plasma (PRP) that stimulate neovascularization and granulation tissue formation. F/P MPs effectively adsorb growth factors and thereby confirmed the previous finding that F/P MPs can significantly enhance neovascularization and filtration of inflammatory cells $[41,46]$. Alternatively, the preinjection of PRP and F/P MPs also represents a promising treatment to prevent skin flap necrosis in reconstructive surgery. The study demonstrated that when PRP and F/P MPs were injected into the damaged skin prior to elevation, a notable cell survival and reduction of necrosis were observed [8].

Lately, protamine has been found to be a suitable injectable biomaterial in the field of dental medicine. A DNA/protamine complex paste with appropriate viscosity has demonstrated a bacteriostatic rather than bacteriocidal effect as it efficiently inhibited growth of bacterial species when injected as a dental implant, a drug carrier for gum pocket treatment, and also promoted guided tissue regeneration (GTR) and guided bone regeneration (GBR). Few of the oral bacterial species that can be controlled by the DNA/protamine complex paste include Staphylococcus aureus, Pseudomonas aeruginosa, Porphyromonas gingivalis, and Prevotella intermedia [6].

Furthermore, dalteparin (F; identical to fragmin) and protamine microparticles (F/P MPs) showed a promising therapeutic use in the field of dermatology particularly on hair reconstruction in order to address alopecia. Combined application of PRP and F/P MPs as well as PRP alone 
TABLE 2: Applications of F/P micro/nanoparticles (F/P M/NPs) as biomaterials for tissue engineering and regenerative medicine.

Biomaterial uses of $\mathrm{F} / \mathrm{P}$ micro/nanoparticles $(\mathrm{F} / \mathrm{P}$ M/NPs)

(1) Heparin neutralizer

(2) Cell carriers
Reported results
Year of publication References

(i) Protamine is a competent heparin neutralizer

(ii) Postimplantation administration of protamine reduced the thrombotic complication and remarkably reduced the lengthy bed rest period as well as the hospital stay of the patients

1997

(iii) Post-protamine injection reactions of the patients such as transient back pain, hypotension, and skin rashes were well managed in vitro

(iv) Severe groin hematoma was observed at a minimal percentage

(i) F/P MPs enhanced the viabilities of various stem cells such as hMVECs, human dermal fibroblasts, and ADSCs in suspension culture

(ii) F/P MPs adhered into the surfaces of the cells, induced cell aggregation, and promoted cell growth

(iii) Cell aggregates secreted increased amount of heparin-binding growth factors such as FGF

(iv) F/P MPs induced neovascularization in nude mice model

(v) Possible angiogenic biomaterial

(i) When F/P MPs were coated on the culture plate, the quiescent state of hepatic stellate RI-T cells (HSCs) was conserved in comparison to those grown under noncoated and matrigel-coated plates

(ii) HSCs exhibited suppressed the expressions of collagen I $\alpha$ I and TGF- $\beta 1$ mRNA levels

(i) F/P NPs reduced the expansion period of human multilineage ASCs and BMSCs despite the absence of animal serum

(ii) F/P NPs induced rapid proliferation rates of ASCs and BMSCs

(iii) ASCs and BMSCs maintained their markers and exhibited their rapid multilineage differentiation

(iv) F/P NP-coated plates are a useful substratum for the adherence and proliferation of ASCs and BMSCs despite low levels of PRP and FGF-2

(i) F/P rapid cell proliferation rate of IR-ASCs under 3D-culture gel system at a low inbred-rat serum content

(ii) F/P expedited not only the local cell proliferation but also the vascularization and tissue granulation at the injection sites after transplantation

(i) Heparin MPs coating immobilized cytokines, namely, SCF, Tpo, and Flt-3 ligand

(3) Cytokine immobilizer or attractant/biomaterial for cell growth and differentiation

2009

demonstrated to occur within 3-4 culture days

(iii) Superior CD $34(+)$ hematopoietic progenitor cells proliferation rates were shown at approximately 8.0-fold and over 31.9-fold after 6 and after 12 culture days, respectively

(i) F/P controlled the gradual release of heparin-binding growth factors like FGF-2 and cytokines such as IL-3 and GM-CSF into the culture media

(ii) F/P enhanced the cell growth of hMVECs, human dermal fibroblast cells (hDFCs), and hematopoietic cell line (TF-1) cells when they were used coating agents despite the low level of FBS in the culture media 
TABLE 2: Continued.

Biomaterial uses of $\mathrm{F} / \mathrm{P}$ micro/nanoparticles (F/P $\mathrm{M} / \mathrm{NPs}$ )

(4) Hair growth enhancer

(5) DNA/protamine injectable dental complex/drug carrier

(6) Protein carrier
Reported results

Year of publication References

(i) Dalteparin (F; identical to fragmin) and protamine microparticles injection (F/P MPs) facilitated increased hair growth

(ii) Microscopic findings showed thickened epithelium, proliferation of collagen fibers and fibroblasts, and increased vessels around follicles

(iii) F/P MPs showed a promising therapeutic use in dermatology particularly on hair reconstruction for alopecia

(i) DNA/protamine complex delayed the growth of certain bacterial species, namely, Staphylococcusaureus, Pseudomonas aeruginosa,

Porphyromonas gingivalis, and Prevotella intermedia

(ii) An effective drug carrier for gum pocket treatment

(iii) DNA/protamine complex promoted GTR and GBR

(i) F/P MPs are competent carrier of the proteins present in the human PRP that stimulate neovascularization and granulation tissue formation

(ii) F/P MPs effectively adsorb growth factors GFs

(iii) F/P MPs significantly enhanced neovascularization and filtration of inflammatory cells

(i) F/P MPs are good carriers of proteins in PRP and optimized the growth of human aorta endothelial cells (AECs) as well as smooth muscle cells(SMCs)

(ii) Superior biological activities of GFs in PRP were demonstrated by the cultured AEC and SMCs treated with F/P MPs

(iii) The increases in collateral arteries in ischemic limbs were significantly higher in the PRP-containing F/P MPs group than those in the F/P MPs alone, and PRP alone, in comparison to the control group.

(7) Injectable biomaterial to prevent skin flap necrosis (i) Injection of PRP and F/P MPs prior to elevation of skin flaps enriched their survival and prohibited necrosis in rodent models

(ii) Histological analysis revealed that the skin flaps preinjected with PRP\&F/P MPs exhibited thick granulation of tissues and neovascularization in comparison to the untreated groups

(iii) PRP and F/P MPs are a promising injectable biomaterial in reconstructive surgery to prevent skin flap necrosis

(i) FGF-2 was bounded to F/P MPs and facilitated its protections against degradation, controlled release during the culture period

(ii) A week after injection, F/P MPs stimulated significant neovascularization and fibrous tissue formation

(8) Growth factor (HGF,VEGF) carrier and inducer of neovascularization (iii) F/P MPs biodegradation was observed 2 weeks after injection

(i) No significant difference in blood pressure among the rabbit animal models of ischemia as revealed by laser Doppler perfusion imaging

(ii) A remarkable improvement of blood pressure was observable in animals treated with F/P MPs/FGF-2 compared to the untreated ones (iii) Cotreatment of F/P MPs and FGF 2 significantly induced collateral blood vessel formation in rabbit ischemic models

(iv) F/P MPS/FGF 2-induced arteriogenesis and angiogenesis in ischemic limbs present a promising for peripheral artery disease (PAD)

(i) HGF-containing F/P MPs substantially enhanced mitogenic effect of HGF on cultured human microvascular endothelial cells

(ii) The conjugation of HGF to F/P MPs facilitated the controlled release of HGF and protected these growth factors from heat and proteolytic inactivation

(iii) F/P MPs are efficient HGF carriers that facilitate cell proliferation and vascularization of damaged tissues in mice models 
facilitated hair growth but F/P MPs provided additional hair growth. It has been demonstrated that PRP and F/P MPs induced increase in epithelial cells, collagen synthesis, and fibroblasts proliferation that facilitated rapid hair growth [7]. This advancement on hair regeneration will offer benefit to a number of patients suffering from the different forms of alopecia, a hair loss medical problem. A summary of the uses of fragmin/protamine under the concept of drug repositioning in tissue engineering and regenerative medicine is presented in Table 2.

Taken together, the uses of fragmin and protamine have evolved from being simple drugs against thromboembolism to DVT prophylaxis, and eventually as insulin stabilizer in the mid-1990s. In the succeeding decade, these drugs have been repurposed as carriers of various types of growth factors, cells, and cytokines while influencing cell growth and differentiation. Additional uses of F/P MPs have been discovered in the recent times as a DNA carrier dental biomaterial, protein carrier, suppressor of collagen, and mRNA expression and an inducer of neovascularization (Figure 1).

\subsection{Recent Advancement of the Use of Fragmin/Protamine} Nanoparticles in Tissue Engineering and Regenerative Medicine. As the research on stem cell therapy continues to rise, search for the alternative uses of fragmin/protamine also increases dramatically. Hence, our group has also conducted such studies with the goal of producing significant contribution to the field of tissue engineering and regenerative medicine. The succeeding sections include the details of our recent findings. Although most of the studies featured in this paper were focused on F/P MPs, our recent work has been focused on F/P NPs applied as encapsulation and cell aggregation biomaterials.

\subsubsection{Use of Nanoparticles for Microencapsulation of Isolated} Islets. Due to the increasing morbidity and even mortality brought about by diabetes mellitus, a number of studies have been conducted focusing on engineering pancreatic islets [47-49]. We have previously reported that artificial islets can be manufactured from a single cell type, the rat insulinsecreting cell line (RIN-5F), or by coculturing two different cell lines such as RIN-5F and Hep-G2 under shaking mechanism during the culture period $[50,51]$. These pseudoislets can be eventually used as bioartificial pancreas for in vitro functional analysis and drug testing. Further applications of F/P MPs in engineering pancreas derived from primary stem cells require further studies in order to achieve transplantable bioartificial pancreas. Although, in transplantation, immune complication remains to be a limiting factor that necessitates the recipient to take immune suppression drugs such as cyclosporine $\mathrm{A}$, these immune suppression drugs induce various side effects [52]. Therefore, immunoisolation by using various artificial encapsulation materials has been developed; however, their incomplete biocompatibility causes foreign body reaction against the membranes while many other side effects remain unknown up till the present. For these reasons, the enhancing immunoisolation strategies have been the primary source of interests of the current researches. The term "immunoisolation" refers to the encapsulation of a graft in a selectively permeable membrane to purposively provide protection of the graft against autoimmune responses as well as reduce the occurrence of graft rejection without using immunosuppressive agents. We have developed chondrocyte sheets that can be utilized to encapsulate bioartificial tissues or even cells as new techniques for macroencapsulation and microencapsulation, respectively [53]. Also, we have conducted an investigation that has been focused on pancreatic islet encapsulation using chondrocytes [54]. In addition, our recent study shows that F/P NPs have excellent potentials as biomaterials since they promoted speedy cell encapsulation of the pancreatic islets within a shorter period (unpublished data).

2.3.2. H/P as Cell Carriers-Cell Aggregation. We recently investigated the adhesive properties of $\mathrm{F} / \mathrm{P}$ as carriers of various stem cells. Our data demonstrated that large, viscous cellular aggregates composed of MSCs and H9C2 cells can be easily manufactured at a relatively shorter period when they were mixed with F/P MPs. In this study, the cells cultured via monolayer system were trypsinized and then mixed with different cell delivery agents, including D-PBS, culture medium, fragmin alone, protamine alone, F/P MPs, and mixed lyophilized F/P MPs. In comparison to other cell delivery agents, cells mixed with F/P MPs exhibited superior cell viscosity and adhesion properties [55]. When these cellular aggregates with F/P MPs were transplanted into a cartilage defect model, the cells remain intact and prevented from spreading away from the transplanted site (unpublished data). Taken together, F/P MPs are small molecules that enhance cell aggregation which may be attributed by the opposing electrical charges of both the negatively charged fragmin and the positively charged protamine [55]. F/P MPs are potential, less-expensive alternatives of cytodex and are efficient microcarriers of cells. Therefore, cell aggregation induced by F/P MPs may improve the efficiency of cell therapy and may represent a novel method for cell transplantation.

\section{Conclusions and Future Directions}

In this paper, we have presented an overview on the rapid and profitable contributions of drug repositioning strategies to the advancement of a number of emerging fields of scientific researches. Firstly, drug-based therapy has improved when the medically approved drugs or previously abandoned drugs have been rediscovered for other indications. Secondly, parallel to the manufacturing of advanced tissue-engineered biomaterials in both the preclinical and clinical translation, a remarkable progression of the application of stem cell therapy in regenerative medicine is also notable. In particular, F/P M/NPs are just some of the drugs that lead to the robust development of stem biology, tissue engineering, and regenerative medicine (Figure 2 ).

Over and beyond the time-efficient and cost-effective drug rediscovery, drug repositioning strategies had paved the way to the significant applications of these drugs as promising 


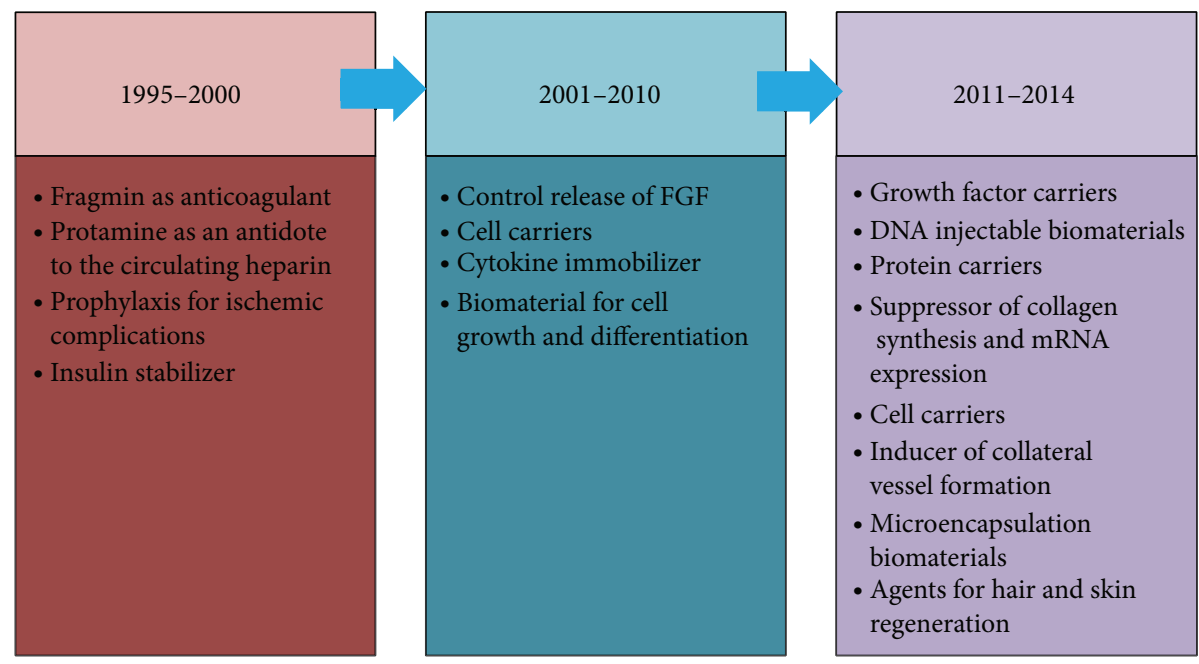

FIGURE 1: Evolution of fragmin and protamine in tissue engineering and regenerative medicine under the concept of drug repositioning. In the mid-1990s, F/P have been primarily used as antagonists of the circulating heparin. By the year of 2000, these drugs have been repurposed as biomaterials that control growth factor release, cell carriers, and cytokine attractant or immobilizer. Lately, more repositioning strategies have been emerging including DNA injectable complex, collagen and mRNA suppressor, protein carriers, and microencapsulation agents.

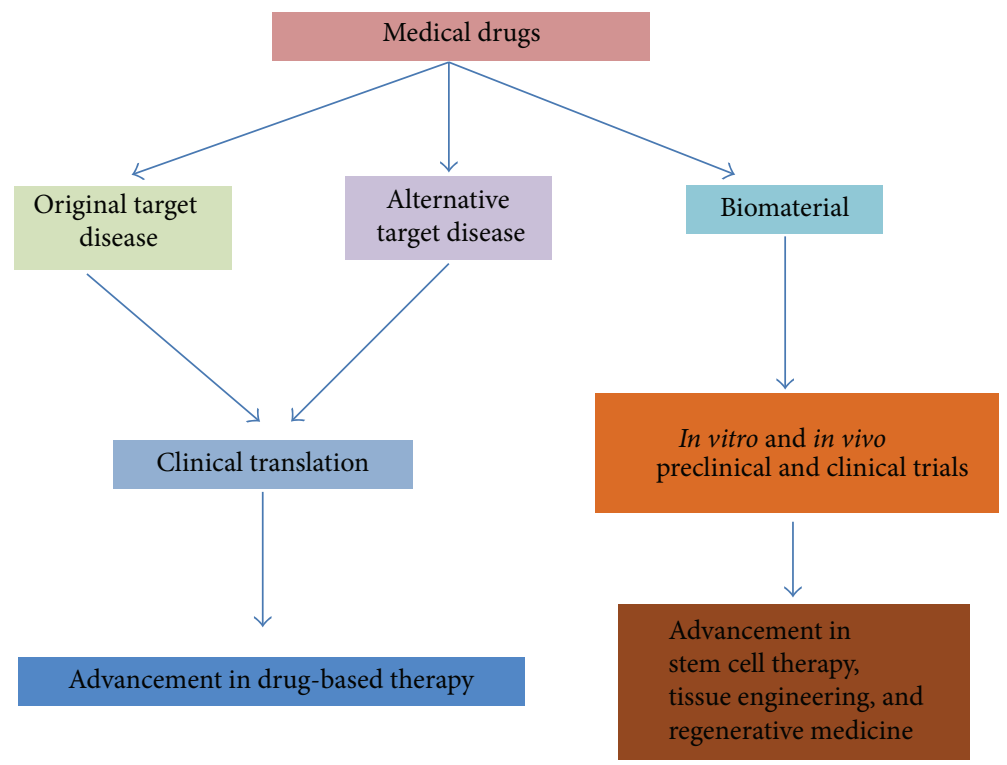

FIGURE 2: The concept of drug repositioning strategy. Drug repurposing strategy has not only brought the progress of drug-based therapy but also paved the way to the advancement of stem cell therapy, tissue engineering, and regenerative medicine.

biomaterials in tissue engineering such that $\mathrm{F} / \mathrm{P}$ has improved cell culture systems, modified cell growth and differentiation, ensured efficient cell/DNA delivery to the target damaged tissues, and possibly manufactured bioartificial pancreatic islets through microencapsulation techniques. Furthermore, $\mathrm{F} / \mathrm{P}$ has been demonstrated to enhance neovascularization and rejuvenation of damaged organs, including hair and skin flaps (Figure 3). These data suggest that $\mathrm{F} / \mathrm{P}$ repurposing is a promising strategy to improve tissue or organ regeneration.

The first engineered bioartificial pancreas and human bladder $[56,57]$ have been reported earlier. However, very recently, Takebe et al. were the first to successfully generate functional and well-vascularized human liver bud transplant from pluripotent stem cells as a promising regenerative strategy to address organ donor scarcity [58]. Therefore, it can be expected that biofabrication of other fully biomimetic tissues or organ buds can be achieved in a not so distant future through the integrated application of drug repositioning, stem cell therapy, and tissue engineering that may possibly reduce the demand for organ donors and immune complication. Finally, we believe that researches focused on F/P will continue to grow and that more drugs will be repurposed not only in tissue engineering and regenerative medicine but also in other related fields. 


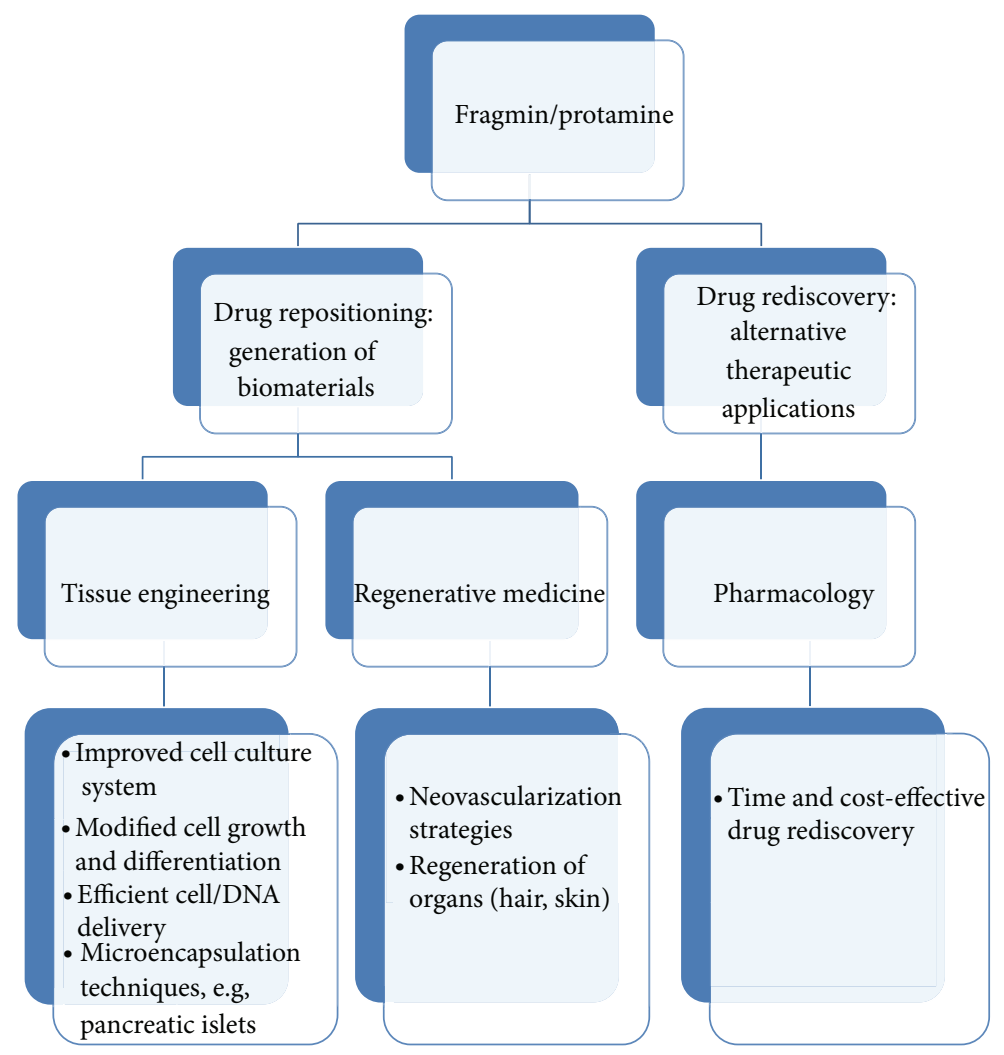

FIGURE 3: Fragmin/protamine repurposing expedited progress of pharmacology, tissue engineering, and regenerative medicine. Repositioning of $\mathrm{F} / \mathrm{P}$ paved the way to a time and cost-effective drug rediscovery while their applications of $\mathrm{F} / \mathrm{P}$ in tissue engineering and regenerative medicine resulted in cell culture systems; modified cell growth and differentiation; efficient protein, cell, and DNA delivery; and enhanced microencapsulation techniques, neovascularization, and regeneration of tissues/organs.

\section{Conflict of Interests}

The authors declare that there is no conflict of interests regarding the publication of this paper.

\section{Acknowledgment}

This paper was supported by Basic Science Research Program through the National Research Foundation of Korea (NRF) funded by the Ministry of Education, Science and Technology (2013R1A2A2A01015327).

\section{References}

[1] H. S. Lee, T. Bae, J. H. Lee et al., "Rational drug repositioning guided by an integrated pharmacological network of protein, disease and drug," BMC Systems Biology, vol. 6, article 80, 2012.

[2] F. S. Collins, "Mining for therapeutic gold," Nature Reviews Drug Discovery, vol. 10, no. 6, p. 397, 2011.

[3] M. S. Shey, E. J. Kongnyuy, S. M. Alobwede, and C. S. Wiysonge, "Co-formulated abacavir-lamivudine-zidovudine for initial treatment of HIV infection and AIDS," The Cochrane Database of Systematic Reviews, vol. 3, Article ID CD005481, 2013.

[4] T. Horio, M. Fujita, Y. Tanaka et al., "Efficacy of fragmin/protamine microparticles containing fibroblast growth factor-2 (F/P
MPs/FGF-2) to induce collateral vessels in a rabbit model of hindlimb ischemia," Journal of Vascular Surgery, vol. 54, no. 3, pp. 791-798, 2011.

[5] S. Kishimoto, M. Ishihara, S. Nakamura et al., "Fragmin/protamine microparticles to adsorb and protect HGF and to function as local HGF carriers in vivo," Acta Biomaterialia, vol. 9, no. 1, pp. 4763-4770, 2013.

[6] T. Fukushima, J. Ohno, R. Imayoshi et al., "DNA/protamine complex paste for an injectable dental material," Journal of Materials Science: Materials in Medicine, vol. 22, no. 12, pp. 2607-2615, 2011

[7] M. Takikawa, S. Nakamura, S. Nakamura et al., "Enhanced effect of platelet-rich plasma containing a new carrier on hair growth," Dermatologic Surgery, vol. 37, no. 12, pp. 1721-1729, 2011.

[8] M. Takikawa, Y. Sumi, M. Ishihara et al., "PRP\&F/P MPs improved survival of dorsal paired pedicle skin flaps in rats," Journal of Surgical Research, vol. 170, no. 1, pp. e189-e196, 2011.

[9] A. L. Hopkins, "Network pharmacology: the next paradigm in drug discovery," Nature Chemical Biology, vol. 4, no. 11, pp. 682690, 2008.

[10] T. I. Oprea and J. Mestres, "Drug repurposing: far beyond new targets for old drugs," AAPS Journal, vol. 14, no. 4, pp. 759-763, 2012.

[11] D. L. Ma, D. S. H. Chan, and C. H. Leung, "Drug repositioning by structure-based virtual screening," Chemical Society Reviews, vol. 42 , no. 5, pp. 2130-2141, 2013. 
[12] F. Bénard, S. Carrier, J. C. Lee, V. Talwar, and I. Defoy, "Men with mild erectile dysfunction benefit from sildenafil treatment," Journal of Sexual Medicine, vol. 7, no. 11, pp. 3725-3735, 2010.

[13] S. Y. Martsevich, S. N. Tolpygina, Y. V. Lukina et al., "Comparative evaluation of antiplatelet efectiveness drugs of original and reproduced enteric forms of acetylsalicylic acid (clinical study ICAR)," Kardiologiya, vol. 52, no. 1, pp. 74-82, 2012.

[14] D. T. Scow, R. S. Nolte, and A. F. Shaughnessy, "Medical treatments for balding in men," American Family Physician, vol. 59, no. 8, pp. 2189-2194, 1999.

[15] M. T. Mizwicki, M. Fiala, L. Magpantay et al., "Tocilizumab attenuates inflammation in ALS patients through inhibition of IL6 receptor signaling," The American Journal of Neurodegenerative Disease, vol. 1, no. 3, pp. 305-315, 2012.

[16] S. Shinriki, H. Jono, K. Ota et al., "Humanized anti-interleukin6 receptor antibody suppresses tumor angiogenesis and in vivo growth of human oral squamous cell carcinoma," Clinical Cancer Research, vol. 15, no. 17, pp. 5426-5434, 2009.

[17] A. L. Smith and A. J. Wein, "Urinary incontinence-pharmacotherapy options," Annals of Medicine, vol. 43, no. 6, pp. 461476, 2011.

[18] H. von der Maase, S. W. Hansen, J. T. Roberts et al., "Gemcitabine and cisplatin versus methotrexate, vinblastine, doxorubicin, and cisplatin in advanced or metastatic bladder cancer: results of a large, randomized, multinational, multicenter, phase III study," Journal of Clinical Oncology, vol. 18, no. 17, pp. 30683077, 2000.

[19] P. D'Amelio and G. C. Isaia, "The use of raloxifene in osteoporosis treatment," Expert Opinion on Pharmacotherapy, vol. 14, no. 7, pp. 949-956, 2013.

[20] K. A. Perkins, J. L. Karelitz, N. C. Jao, and E. Stratton, "Possible reinforcement enhancing effects of bupropion during initial smoking abstinence," Nicotine and Tobacco Research, vol. 15, no. 6, pp. 1141-1145, 2013.

[21] D. Stough, "Dutasteride improves male pattern hair loss in a randomized study in identical twins," Journal of Cosmetic Dermatology, vol. 6, no. 1, pp. 9-13, 2007.

[22] S. Singhal, J. Mehta, R. Desikan et al., "Antitumor activity of thalidomide in refractory multiple myeloma," New England Journal of Medicine, vol. 341, no. 21, pp. 1565-1571, 1999.

[23] K. R. Sando and J. Taylor, "Bromocriptine: its place in type 2 diabetes Tx," Journal of Family Practice, vol. 60, no. 11, pp. E1E5, 2011.

[24] I. Ahmed, "Ropinirole in restless leg syndrome," Missouri Medicine, vol. 99, no. 9, pp. 500-501, 2002.

[25] P. Miheller, L. S. Kiss, M. Mandel, and P. L. Lakatos, "Methotrexate: should we start using it in clinical practice?" Current Drug Targets, vol. 14, no. 12, pp. 1480-1489, 2013.

[26] A. H. A. Mohamed-Ahmed, S. Brocchini, and S. L. Croft, "Recent advances in development of amphotericin B formulations for the treatment of visceral leishmaniasis," Current Opinion in Infectious Diseases, vol. 25, no. 6, pp. 695-702, 2012.

[27] J. Brotchie, "Antidyskinetic actions of amantadine in Parkinson's disease: are benefits maintained in the long term?" Expert Review of Neurotherapeutics, vol. 10, no. 6, pp. 871-873, 2010.

[28] R. A. Moore, "Review: gabapentin reduces some types of chronic neuropathic pain more than placebo in adults," Annals of Internal Medicine, vol. 155, no. 2, article JC1-8, 2011.

[29] S. K. H. Khalil, G. S. El-Feky, S. T. El-Banna, and W. A. Khalil, "Preparation and evaluation of warfarin- $\beta$-cyclodextrin loaded chitosan nanoparticles for transdermal delivery," Carbohydrate Polymers, vol. 90, no. 3, pp. 1244-1253, 2012.
[30] M. Waisbourd, G. Shemesh, S. Kurtz et al., “Topical bevacizumab for neovascular glaucoma: a pilot study," Pharmacology, vol. 93, no. 3-4, pp. 108-112, 2014.

[31] L. Shen, J. Li, J. Xu et al., "Bevacizumab plus capecitabine and cisplatin in Chinese patients with inoperable locally advanced or metastatic gastric or gastroesophageal junction cancer: randomized, double-blind, phase III study (AVATAR study)," Gastric Cancer, 2014.

[32] M. Dithmer, S. Fuchs, Y. Shi et al., "Fucoidan reduces secretion and expression of vascular endothelial growth factor in the retinal pigment epithelium and reduces angiogenesis in vitro," PLoS ONE, vol. 9, no. 2, Article ID e89150, 2014.

[33] S. Lee, B. Y. Kim, J. E. Yeo et al., "New culture medium concepts for cell transplantation," Transplantation Proceedings, vol. 45, no. 8, pp. 3108-3112, 2013.

[34] H. C. Hagedorn, "Protamine insulinate: section of therapeutics and pharmacology," Proceedings of the Royal Society of Medicine, vol. 30, no. 6, pp. 805-814, 1937.

[35] D. K. Burnham, "Insulin and insulin mixtures; nph insulin," California Medicine, vol. 75, no. 6, pp. 412-415, 1951.

[36] Scott, D. A, and A. M. Fisher, "Studies on insulin with protamine," Journal of Pharmacology and Experimental Therapeutics, vol. 58, no. 1, pp. 78-92, 1936.

[37] M. Pan, J. Suárez de Lezo, A. Medina et al., "In-laboratory removal of femoral sheath following protamine administration in patients having intracoronary stent implantation," American Journal of Cardiology, vol. 80, no. 10, pp. 1336-1338, 1997.

[38] N. Ramamurthy, N. Baliga, T. W. Wakefield, P. C. Andrews, V. C. Yang, and M. E. Meyerhoff, "Determination of lowmolecular-weight heparins and their binding to protamine and a protamine analog using polyion-sensitive membrane electrodes," Analytical Biochemistry, vol. 266, no. 1, pp. 116-124, 1999.

[39] S. Nakamura, S. Kishimoto, S. I. Nakamura et al., "Frag$\mathrm{min} /$ protamine microparticles as cell carriers to enhance viability of adipose-derived stromal cells and their subsequent effect on in vivo neovascularization," Journal of Biomedical Materials Research A, vol. 92, no. 4, pp. 1614-1622, 2010.

[40] Y. Sumi, M. Ishihara, S. Kishimoto et al., "Transplantation of inbred adipose-derived stromal cells in rats with plasma gel containing fragmin/protamine microparticles and FGF-2," Journal of Biomedical Materials Research B: Applied Biomaterials, vol. 101, no. 5, pp. 784-791, 2013.

[41] S. Nakamura, Y. Kanatani, S. Kishimoto et al., "Controlled release of FGF-2 using fragmin/protamine microparticles and effect on neovascularization," Journal of Biomedical Materials Research A, vol. 91, no. 3, pp. 814-823, 2009.

[42] S. Kishimoto, M. Ishihara, Y. Mori et al., "Effective expansion of human adipose-derived stromal cells and bone marrow-derived mesenchymal stem cells cultured on a frag$\mathrm{min}$ /protamine nanoparticles-coated substratum with human platelet-rich plasma," Journal of Tissue Engineering and Regenerative Medicine, vol. 7, no. 12, pp. 955-964, 2013.

[43] H. Sekiguchi, N. Hemmi, T. Maki et al., "Culture on a Fragmin/protamine-coated plate suppresses the collagen type I $\alpha$ I and TGF- $\beta 1$ mRNA expression of rat hepatic stellate RI-T cells," Journal of Veterinary Medical Science, vol. 75, no. 5, pp. 553-559, 2013.

[44] S. Kishimoto, S. Nakamura, S. I. Nakamura et al., "Cytokineimmobilized microparticle-coated plates for culturing hematopoietic progenitor cells," Journal of Controlled Release, vol. 133, no. 3, pp. 185-190, 2009. 
[45] M. Fujita, T. Horio, S. Kishimoto et al., "Effects of plateletrich plasma-containing fragmin/protamine microparticles in enhancing endothelial and smooth muscle cell growth and inducing collateral vessels in a rabbit model of hindlimb ischemia," Journal of Biomedical Materials Research B: Applied Biomaterials, vol. 101, no. 1, pp. 36-42, 2013.

[46] M. Takikawa, S. I. Nakamura, S. Nakamura et al., "Enhancement of vascularization and granulation tissue formation by growth factors in human platelet-rich plasma-containing frag$\mathrm{min}$ /protamine microparticles," Journal of Biomedical Materials Research B: Applied Biomaterials, vol. 97, no. 2, pp. 373-380, 2011.

[47] Z. Li, H. Sun, J. Zhang, H. Zhang, F. Meng, and Z. Cui, "Development of in vitro 3D tissueflex islet model for diabetic drug efficacy testing," PLoS ONE, vol. 8, no. 8, Article ID e72612, 2013.

[48] E. C. Opara, S. H. Mirmalek-Sani, O. Khanna, M. L. Moya, and E. M. Brey, "Design of a bioartificial pancreas," Journal of Investigative Medicine, vol. 58, no. 7, pp. 831-837, 2010.

[49] T. Orlowski, E. Sitarek, K. Tatarkiewicz, M. Sabat, and M. Antosiak, "Comparison of two method of pancreas islets immonoisolation," International Journal of Artificial Organs, vol. 20, no. 12, pp. 701-703, 1997.

[50] D. J. Joo, J. Y. Kim, J. I. Lee et al., "Manufacturing of insulinsecreting spheroids with the RIN-5F cell line using a shaking culture method," Transplantation Proceedings, vol. 42, no. 10, pp. 4225-4227, 2010.

[51] J. Y. Kim, H. W. Kim, S. J. Bae et al., "Hybrid cellular spheroids from hepatocellular carcinoma and insulin-secreting cell lines," Transplantation Proceedings, vol. 44, no. 4, pp. 1095-1098, 2012.

[52] O. A. Gheith, M. A. Bakr, M. A. Fouda, A. A. Shokeir, M. Sobh, and M. Ghoneim, "Comparative analysis of azathioprine versus cyclosporine-based therapy in primary haplo-identical live-donor kidney transplantation: a 20-year experience," Saudi Journal of Kidney Diseases and Transplantation, vol. 19, no. 4, pp. 564-570, 2008.

[53] J. I. Lee, R. Nishimura, H. Sakai, N. Sasaki, and T. Kenmochi, "A newly developed immunoisolated bioartificial pancreas with cell sheet engineering," Cell Transplantation, vol. 17, no. 1-2, pp. 51-59, 2008.

[54] J. I. Lee, H. W. Kim, J. Y. Kim et al., "Microencapsulation of pancreatic islets with canine ear cartilage for immunoisolation," Transplantation Proceedings, vol. 44, no. 4, pp. 1091-1094, 2012.

[55] J. E. Yeo, B. M. Nam, W. Yang et al., "Fragmin/protamine microparticle carriers as a drug repositioning strategy for cell transplantation," Transplantation Proceedings, vol. 45, no. 8, pp. 3122-3126, 2013.

[56] A. Atala, "Tissue engineering of human bladder," British Medical Bulletin, vol. 97, no. 1, pp. 81-104, 2011.

[57] J. J. Yoo, J. Olson, A. Atala, and B. Kim, "Regenerative medicine strategies for treating neurogenic bladder," International Neurourology Journal, vol. 15, no. 3, pp. 109-119, 2011.

[58] T. Takebe, K. Sekine, M. Enomura et al., "Vascularized and functional human liver from an iPSC-derived organ bud transplant," Nature, vol. 499, no. 7459, pp. 481-484, 2013. 


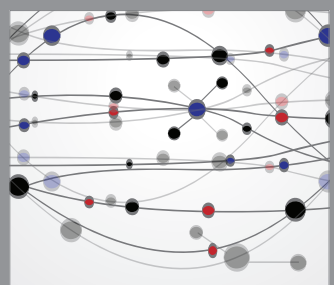

The Scientific World Journal
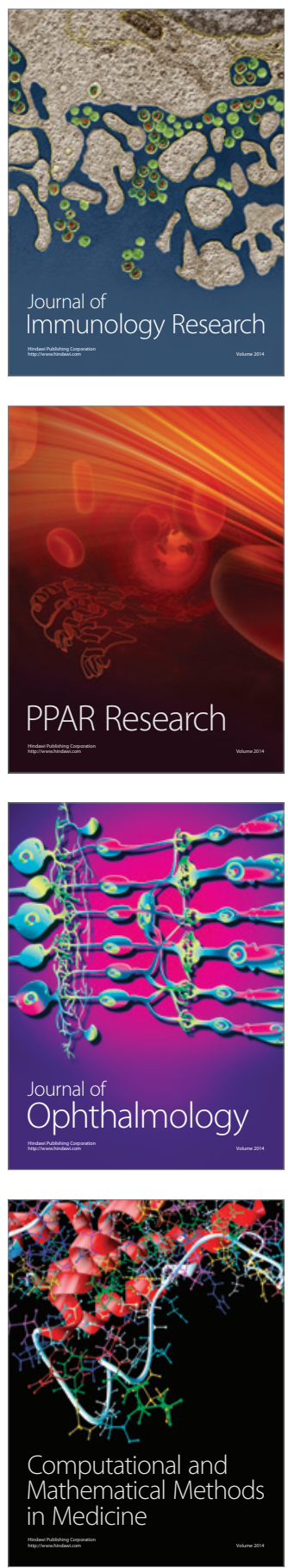

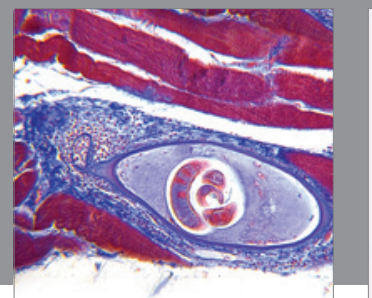

Gastroenterology

Research and Practice
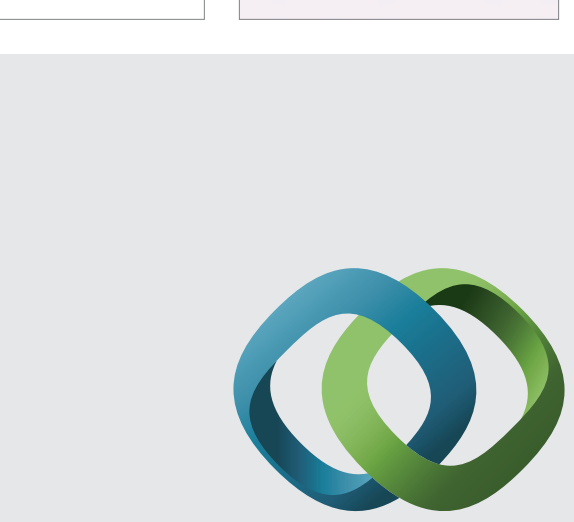

\section{Hindawi}

Submit your manuscripts at

http://www.hindawi.com
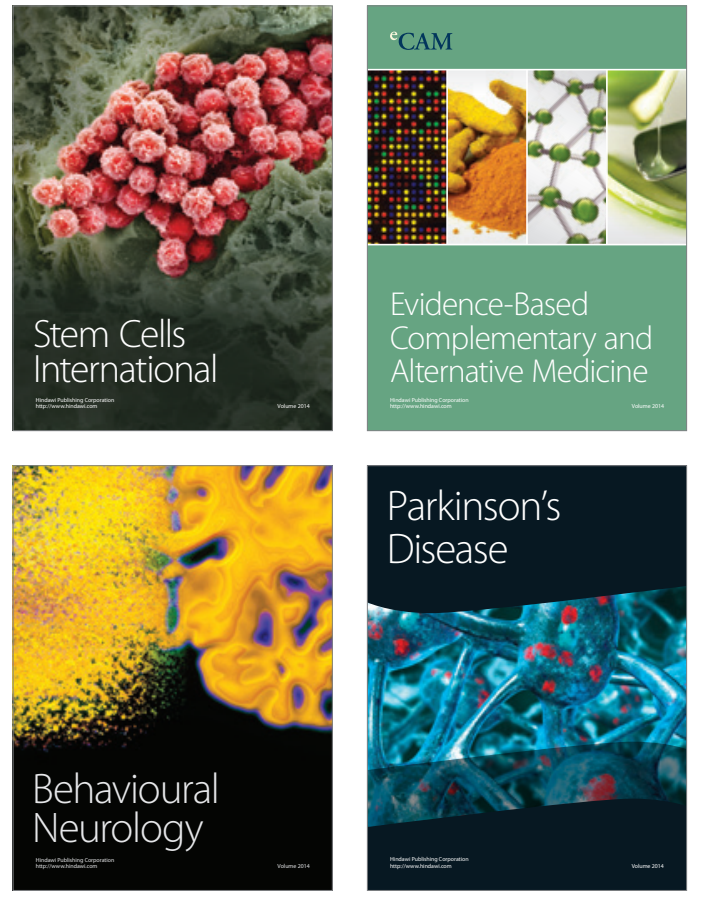
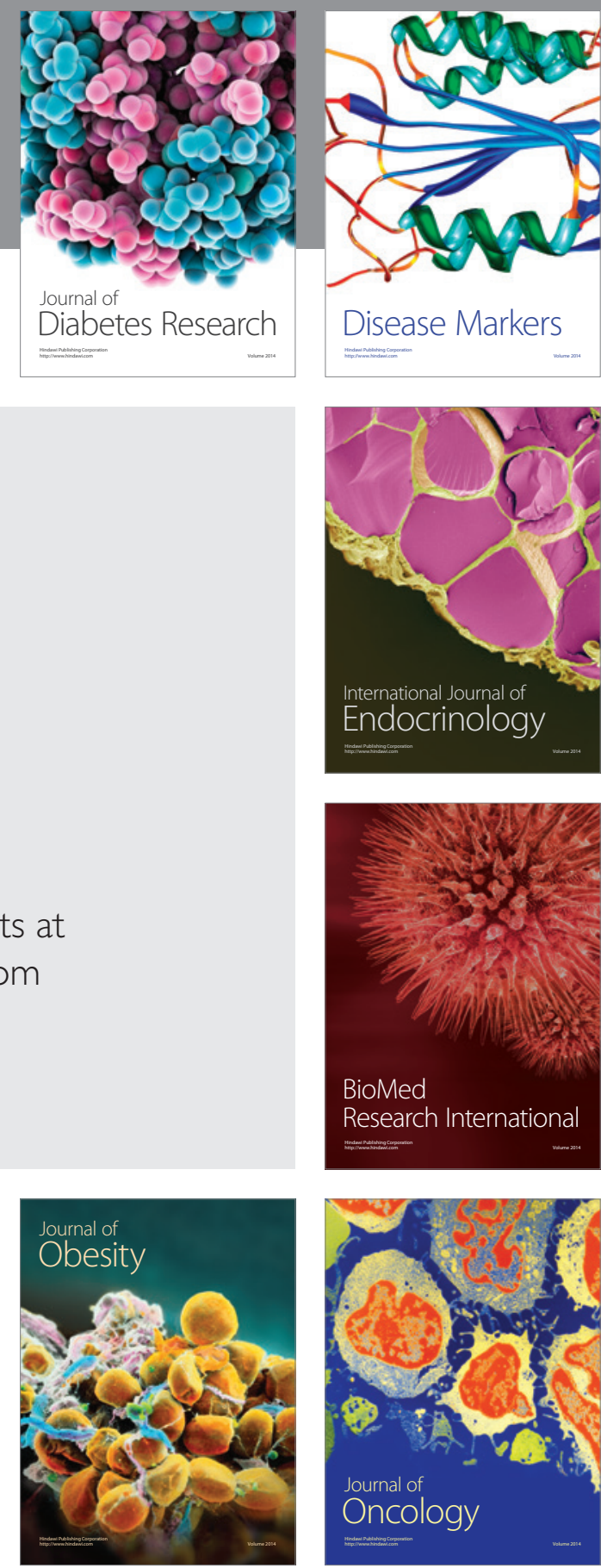

Disease Markers
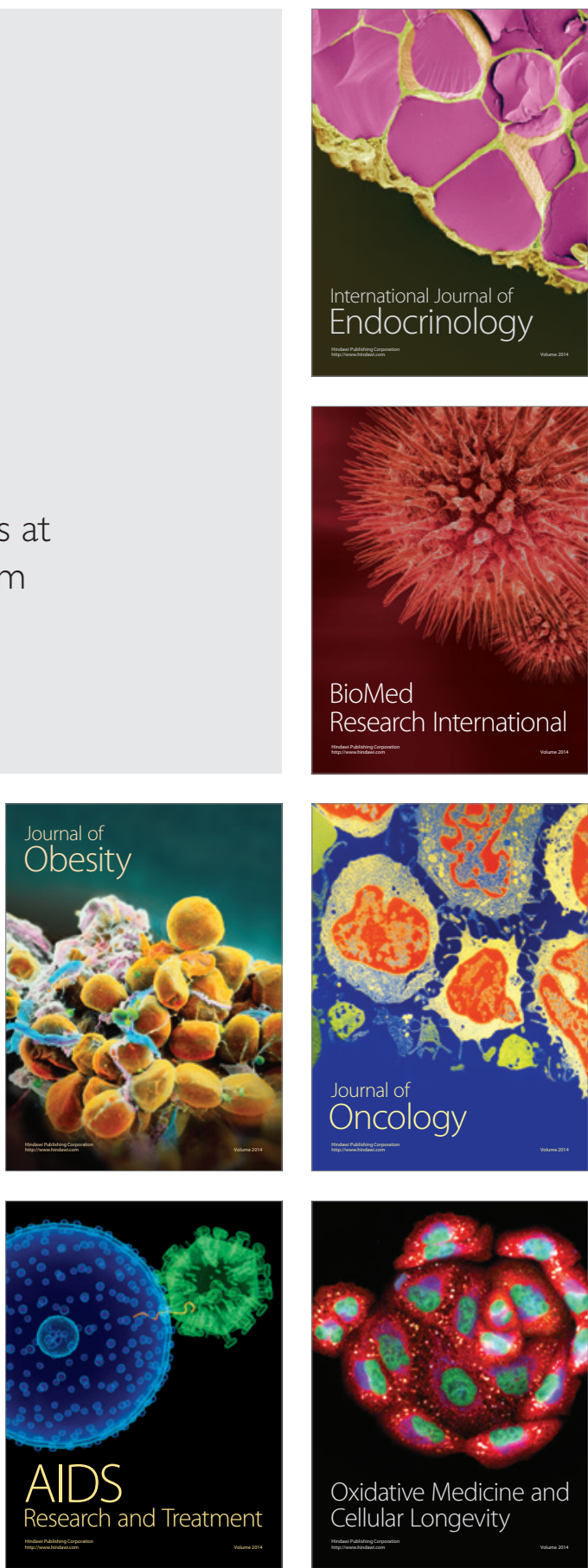